\title{
Mixed Connective Tissue Disorder Associated with Scleroderma Renal Crisis
}

Imran Khan $^{1 *}$, Irfan Khan ${ }^{2}$, Tahir Ahmad ${ }^{1}$ and Huma Noor ${ }^{1}$

${ }^{1}$ Department of General Medicine, Sheri-Kashmir Institute of Medical Sciences, Srinagar, Jammu and Kashmir, India

2Department of Pathology, Government Medical College Jammu, Jammu and Kashmir, India

*Corresponding author: Imran Khan, Department of General Medicine, Sheri-Kashmir Institute of Medical Sciences, Srinagar, Jammu and Kashmir, India, Tel: 91-194-2401013; E-mail: 845docimran@gmail.com

Rec date: Dec 17, 2013, Acc date: Feb 18, 2014, Pub date: Feb 25, 2014

Copyright: @ 2014 Khan I, et al. This is an open-access article distributed under the terms of the Creative Commons Attribution License, which permits unrestricted use, distribution, and reproduction in any medium, provided the original author and source are credited.

\begin{abstract}
Mixed connective tissue disease (MCTD) is a rheumatic disease with a combination of multiple connective tissue disorders, which includes dermatomyositis or polymyositis, systemic sclerosis, systemic lupus erythematosus, rheumatoid arthritis and Sjogren's syndrome. Renal involvement in mixed connective tissue disorder is a rare occurrence. We present a case of MCTD presenting with SRC managed with ACE Inhibitor (Captopril). The patient had advanced renal failure and presently on maintenance haemodialysis.
\end{abstract}

Keywords: Mixed connective tissue disorder; Sjogren's syndrome; Scleroderma renal crisis; Polymyositis

\section{Abbreviations:}

MCTD: Mixed Connective Tissue Disease; SRC: Scleroderma Renal Crisis; ACEi: Angiotensin-Converting Enzyme Inhibitor

\section{Introduction}

Mixed connective tissue disease (MCTD) is an overlap syndrome characterised by a combination of connecting tissue diseases, including systemic sclerosis, systemic lupus erythematosus, polymyositis, Sjogren's syndrome and arthritis associated with antibodies to RNA-sensitive extractable nuclear antigen [1].

Kidney involvement in the form of Scleroderma renal crisis in mixed connective tissue disorder is a rare event. Although, Scleroderma renal crisis is well known in scleroderma patients. Scleroderma renal crisis has been identified by the clinical characteristics, and by characteristic renal lesion suggestive of malignant hypertension [2,3]. The literature regarding mixed connective tissue disorder presenting with Scleroderma renal crisis is limited to a few case reports.

\section{Case Report}

We present a case of Mixed Connective Tissue disorder presenting with Scleroderma renal crisis. 36 years female, parity of five, normal menstrual history. The illness started two years back with chief complaints history of Raynaud's phenomenon, arthralgias, multiple joints swelling of hands. The patient systemic therapy included methotrexate, folic acid, NSAIDS. She presented to us with complaints of blurring of vision in right eye, headache, oliguria, facial puffiness and arthralgias. Physical examination revealed pallor, periorbital puffiness, pedal oedema with pulse rate of $86 / \mathrm{min}$, B.P.- $150 / 90 \mathrm{mmHg}$. Local examination revealed swelling of fingers and palms, tendernessMCP, PIP joints of both hands. Investigations were as Table 1.

Urine examination: Granular cast present, albumin 1+. Twentyfour hour urinary protein was $1.04 \mathrm{~g} / 24 \mathrm{hrs}$. Ultrasound of kidneys revealed rt kidney-9.7 x $3.6 \mathrm{~cm}$ lt kidney- 8.4 x $3.9 \mathrm{~cm}$ bilateral corticomedullary differentiation was maintained.

\begin{tabular}{|l|l|l|l|l|l|l|}
\hline Hb & TLC & MCV & Plt & ESR & Urea & Creatnine \\
\hline 10.4 & 9800 & 85 & 123 & 43 & 109 & 2.5 \\
\hline Bil & ALT & AST & Protein & Albumin & Ca & Phosp \\
\hline 1.0 & 32 & 38 & 6.4 & 3.4 & 9.1 & 3.2 \\
\hline
\end{tabular}

Table 1: Mixed Connective Tissue disorder presenting with Scleroderma renal crisis

\section{Autoimmune profile}

RF positive (30 IU/ml), Anti-CCP negative $(0.25 \mathrm{U} / \mathrm{ml})$, DNA topoisomerase I negative $(0.52 \mathrm{U} / \mathrm{ml})$, anti-U1 RNP positive $(36.2 \mathrm{U} /$ $\mathrm{ml})$, ANA positive.

Renal Biopsy was performed in the patient after stabilisation of hypertension. The findings were as a total of 14 glomeruli were seen. The glomeruli showed non immune complex mediated disease process ischemic collapse with fibrinoid necrosis was seen suggestive of glomerular ischemic changes. The tubules revealed patchy degeneration with interstitial oedema, hyaline cast (Figures 1-3).

The patient was managed with captopril $25 \mathrm{mg}$ Bid dosage and daily monitoring of Blood Pressure was done. The patient B.P remains < 140/90 mm Hg. The patient had been closely followed for 6 months. Her creatinine remains in the range of 2.5-3.0 and target control of B.P. is achieved with Captopril. For long-term management of Renal replacement options have been kept in mind and discussed with patient and family. 


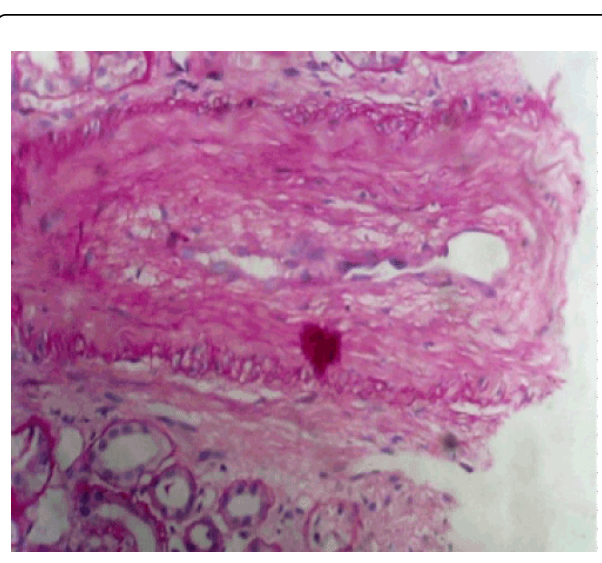

Figure 1: Accelerated Hypertension related vascular changes

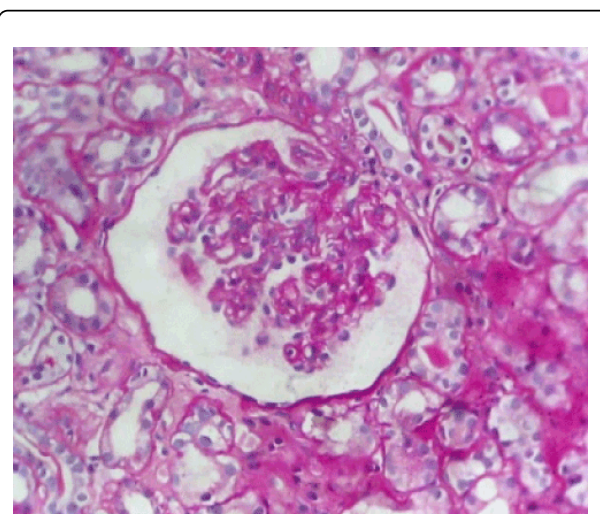

Figure 2: Non immune complex mediated disease process exhibiting glomerular ischemic changes

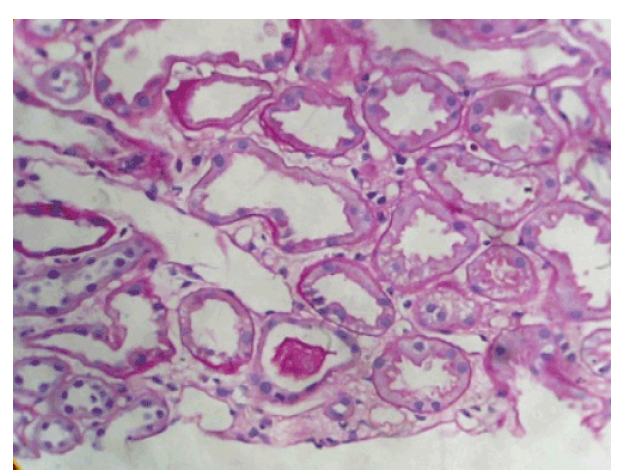

Figure 3: Patchy acute tubular injury with interstitial edema and hyaline cast

\section{Discussion}

Mixed connective tissue disease (MCTD) was originally defined in 1972 as a connective tissue disorder characterized by a combination of multiple connective tissue disorders, which includes dermatomyositis or polymyositis, systemic sclerosis, systemic lupus erythematosus, rheumatoid arthritis and Sjogren's syndrome and the presence of high titers of a distinctive autoantibody, now called anti-U1 ribonucleoprotein (RNP) [4].

A population-based study in Norway found the point prevalence rate to be 3.8 cases per 100,000 adult populations. The female-to-male ratio of MCTD is approximately 3:1. The onset of MCTD can occur at any age but typically occurs in people aged 15-25 years [5]. The primary process is injury of the endothelial cells, which results in intimal thickening and intimal proliferation of renal intralobular and arcuate arteries. The thickened abnormal vessel wall allows platelet aggregation and adhesion to occur. Release of platelet factors increases vascular permeability and may participate in the production of increased collagen and fibrin deposition that contribute to the luminal narrowing [6].

MCTD affecting renal system is not a common occurrence. The medical literature regarding involvement of renal vasculature in the MCTD with features of scleroderma renal crisis is limited to a few sporadic reports [7-10].

The manifestation of renal involvement in MCTD are follows: proliferative glomerulonephritis, membranous glomerulonephritis, amyloidosis or interstitial nephritis and SRC. The typical clinical presentation of SRC is as accelerated phase hypertension and progressive renal impairment, hypertensive retinopathy, encephalopathy and microangiopathic haemolytic anaemia. Laboratory features reveal non-nephrotic range proteinuria and haematuria [11]. Vancheeswaran et al. described the criteria for SRC (accelerated hypertension, abnormal renal function and fall in creatinine clearance) [12]. Renal biopsy is not routinely required in SRC. It rather, is being done when doubt exists about the underlying disease or to exclude another concurrent pathological process [13]. In the present case, accelerated blood pressure, renal involvement in the form of rising creatnine and vasculopathic changes of glomeruli points to the diagnosis of SRC due to underlying MCTD. The natural course of unattended SRC is end-stage renal disease that occurs in a short period of 1-2 months. The modality of treatment is effective blood pressure control $(<130 / 80 \mathrm{mmHg})$ with antihypertensive agent Angiotensin- converting enzyme inhibitor e.g., Captopril. Penn et al. reported around one-third (33\%) of patients with SRC remain dialysis dependent on long-term basis (5 years) [14]. Steen and Medsger reported about nineteen percent of SRC patients required maintainence dialysis for survival [15]. The longest reported recovery of renal function following SRC has been eighteen months [7]. In our case, the patient remained on ACEi (captopril) with no recovery of kidney function 3 months after initial presentation. (Sir the patient is following us past one year. I have specifically mentioned 3 months as the definition of Chronic kidney Disease is azotemia for three or more months as per KDIGO guidelines).

Strongwater et al. reported a patient with undifferentiated connective tissue disease with renal failure who responded to enalapril [10]. Andersen and Vasko reported two cases of MCTD having pulmonary and renal insufficiency complicated by SRC which responded to enalapril. They both had features of Raynaud's phenomenon, digital ulcers, and muscle weakness and pulmonary artery hypertension. The second case also had severe polyarthritis and right-sided heart failure. However, despite initial good response in the second case, the patient died of circulatory collapse and, at autopsy, renal biopsy revealed features of SRC [16]. Celikbilek et al. reported a case of MCTD following abortion complicated by SRC and pulmonary involvement which responded to enalapril, steroids and immunosuppression medications [17]. 
Satoh et al. reported a female with MCTD with features of Raynaud's phenomenon, sclerodactyly. She was started on low-dose steroids and, 10 months later, presented with increased blood pressure and renal dysfunction. Renal biopsy was consistent with features of SRC. She responded to ACEi and prostaglandins [18]. Greenberg and Amato et al. reported a case of SRC in MCTD in a female patient with inflammatory myopathy who was started on high-dose steroids which precipitated SRC, leading to chronic kidney disease stage V. Two months following the SRC episode, she was still dialysis-dependent [19]. Our patient probably did not recover because of late diagnosis, existing chronic kidney disease and failure to start ACEi before admission to our hospital. Sir, The review of patient's records revealed that she had been following many physicians and had poor compliance of two years of illness. It was during present illness the diagnosis had been made on proper clinical and immunological background.

\section{Conclusion}

Scleroderma Renal crisis can occurs in patients who have mixed connective tissue disorder. It can be successfully treated with ACE inhibitors. This therapy has improved survival, reduced the requirement for dialysis and prevented the development of chronic kidney disease. Prompt diagnosis and early, aggressive initiation of therapy with ACE inhibitors will result in the most optimal outcome.

Sir, with the background of low compliance and lack of immunological support for the diagnosis for two years, it is likely that the disease had been dealt inadequately. The patient had uncontrolled hypertension but was not on ACEi. After taking ACEi, the normalisation of blood pressure and stabilisation of azotaemia occurred.

\section{References}

1. De Clerck LS, Meijers KA, Cats A (1989) Is MCTD a distinct entity? Comparison of clinical and laboratory findings in MCTD, SLE, PSS, and RA patients. Clin Rheumatol 8: 29-36.

2. Moore HC, Sheehan HL (1952) The kidney of scleroderma. Lancet 1: 68-70.

3. Traub YM, Shapiro AP, Rodnan GP, Medsger TA, McDonald RH, et al. (1983) Hypertension and renal failure (scleroderma renal crisis) in progressive systemic sclerosis. Review of a 25 -year experience with 68 cases. Medicine (Baltimore) 62: 335-352.

4. Sharp GC, Irvin WS, Tan EM, Gould RG, Holman HR (1972) Mixed connective tissue disease--an apparently distinct rheumatic disease syndrome associated with a specific antibody to an extractable nuclear antigen (ENA) Am J Med 52:148-159.

5. Gunnarsson R, Molberg O, Gilboe IM, Gran JT, PAHNOR1 Study Group (2011) The prevalence and incidence of mixed connective tissue disease: a national multicentre survey of Norwegian patients. Ann Rheum Dis 70: 1047-1051.

6. Kahaleh MB, LeRoy C (2002) Progressive systemic sclerosis: kidney involvement. Clin Rheum Dis 5: 167-185.

7. Pope JE (2005) Other manifestations of mixed connective tissue disease. Rheum Dis Clin North Am 31: 519-533, vii.

8. Kitridou RC, Akmal M, Turkel SB, Ehresmann GR, Quismorio FP, et al. (1986) Renal involvement in mixed connective tissue disease: a longitudinal clinicopathologic study. Semin Arthritis Rheum 16: 135-145.

9. Crapper RM, Dowling JP, Mackay IR, Whitworth JA (1987) Acute scleroderma in stable mixed connective tissue disease: treatment by plasmapheresis. Aust N Z J Med 17: 327-329.

10. Strongwater SL, Galvanek EG, Stoff JS (1989) Control of hypertension and reversal of renal failure in undifferentiated connective tissue disease by enalapril. Arch Intern Med 149: 582-585.

11. Denton CP, Lapadula G, Mouthon L, Müller-Ladner U (2009) Renal complications and scleroderma renal crisis. Rheumatology (Oxford) 48 Suppl 3: 32-35.

12. Vancheeswaran R, Magoulas T, Efrat G, Wheeler-Jones C, Olsen I, et al. (1994) Circulating endothelin-1 levels in systemic sclerosis subsets--a marker of fibrosis or vascular dysfunction? J Rheumatol 21: 1838-1844.

13. Batal I, Domsic RT, Medsger TA, Bastacky S (2010) Scleroderma renal crisis: a pathology perspective. Int J Rheumatol 2010: 543704.

14. Penn H, Howie AJ, Kingdon EJ, Bunn CC, Stratton RJ, et al. (2007) Scleroderma renal crisis: patient characteristics and long-term outcomes. QJM 100: 485-494.

15. Steen VD, Medsger TA (2000) Long-term outcomes of scleroderma renal crisis. Ann Intern Med 133: 600-603.

16. Andersen GN, Vasko J (2002) Scleroderma renal crisis and concurrent isolated pulmonary hypertension in mixed connective tissue disease and overlap syndrome: report of two cases. Clin Rheumatol 21: 164-169.

17. Celikbilek M, Elsurer R, Afsar B, Ozdemir HB, Sezer S, et al. (2007) Mixed connective tissue disease: a case with scleroderma renal crisis following abortion. Clin Rheumatol 26: 1545-1547.

18. Satoh K, Imai H, Yasuda T, Wakui H, Miura AB, et al. (1994) Sclerodermatous renal crisis in a patient with mixed connective tissue disease. Am J Kidney Dis 24: 215-218.

19. Greenberg SA, Amato AA (2001) inflammatory myopathy associated with mixed connective tissue disease and scleroderma renal crisis. Muscle Nerve 24: 1562-1566. 